\title{
COVID-19 and Community College Instructional Responses
}

\author{
Cassandra M.D. Hart and Emily Alonso \\ University of California, Davis \\ Di Xu and Michael Hill \\ University of California, Irvine
}

\begin{abstract}
Like all educational institutions, community colleges rapidly shifted to online instruction in the wake of the COVID-19 pandemic. However, little is known about what factors shaped individual college responses. This survey of distance education leaders $(\mathrm{N}=45)$ in the California community colleges system aimed to: (a) characterize pre-COVID distance education resources, emergency responses to the pandemic, and readiness for online instruction in the fall, and (b) determine how pre-COVID distance education resources, emergency responses, and fall readiness relate to each other. We find wide variability in pre-COVID distance education resources. These preexisting resources were related to institutions' responses: Colleges with fewer pre-COVID resources focused on foundational efforts such as creating online student services, while institutions with greater pre-COVID resources offered somewhat broader responses to training students and faculty in skills to successfully transition online. Finally, although colleges improved their readiness for continued remote instruction in the fall term in terms of training faculty and providing students with technology to access classes, respondents estimated that roughly a third of students would still face barriers accessing remote classes.
\end{abstract}

Keywords: online education, distance education, emergency remote instruction, distance learning resources, COVID-19, community colleges

Hart, C.M.D., Xu, D., Hill, M., \& Alonso, E. (2021). COVID-19 and community college instructional responses. Online Learning, 25(1), 41-69.

https://doi.org/10.24059/olj.v25i1.2568 


\section{COVID-19 and Community College Instructional Responses}

In response to the COVID-19 pandemic, colleges nationwide shifted face-to-face instruction to emergency remote teaching in spring 2020 (Hodges et al., 2020). This represented a massive change for many institutions. Prior to the pandemic, the extent to which institutions embraced online and technology-mediated instruction was largely related to institutional culture and philosophy. Some institutions made only modest investments in online instruction due to concerns that it was more challenging to deliver high-quality learning experiences through online classes (Cox, 2005; Martins \& Nunes, 2016). The COVID-19 pandemic forced the hand of institutions slow to embrace online instruction, with little time to plan or build capacity, prepare and train faculty, or provide technical and academic support to students. This type of rapid shift in instruction can have significant impacts on student academic performance (Hill, 2019).

This study investigated the roll-out of emergency remote teaching by administering a survey in the California Community College system (the "CCC" system), which is the largest system of higher education in the nation. Drawing from literature on online teaching and learning, and on institutional conditions that support distance education, we explored community colleges' preexisting distance education resources, institutional responses to the crisis in spring 2020, readiness for fall 2020, and how these three factors relate to one another.

\section{Review of Relevant Literature}

On the surface, the transition of course delivery from on-campus to online may appear straightforward. However, online learning requires planning and resource investment by colleges, as well as skills and abilities on the part of both faculty and students that are distinct from those required in face-to-face environments (Johnson et al., 2015). To understand the relationship between institutional factors and readiness for online instruction, we draw on prior literature to highlight three areas critical to online learning success: student readiness for online learning, faculty training and development, and institutional resources dedicated to distance education.

\section{Online Learning Demands and Removing Barriers to Student Readiness}

At the most basic level, to succeed in online classes, students need computing devices and connectivity to access those classes; yet many students lack such access. A poll of California college students by The Education Trust-West (2020) found that an estimated 13\% of students of color and $14 \%$ of students in low-income households lacked internet access. Similarly, $12 \%$ of students of color and $15 \%$ of low-income students lacked access to a computer or mobile device capable of accessing online courses at their college. The pandemic stymied traditional approaches to mitigating these equity gaps. Prior to the pandemic, campus computer labs, learning resource centers, and libraries could offer computer and network access for online education for students who lacked them at home. The COVID-19 pandemic placed additional strains in requiring that students have these resources at home.

Successful online learning also requires a distinct set of student skills. For instance, navigating new technologies, such as learning management systems and course software, is challenging for many students (Jaggars, 2011; Bambara et al., 2009). Online learning is also more self-directed, requiring students in online settings to focus more on time management and selfmotivation (Quintana et al., 2005; Xu \& Jaggars, 2014). Soft skills for self-efficacy may be particularly important for students from underrepresented minority groups, as prior work on online 
teaching and learning consistently indicates that these students tend to have poorer outcomes in online learning environments (e.g., Hart et al., 2018). In addition, students should be familiar with the nature of online tools and resources that are available, expectations for online learning, and strategies for success (Harasim et al., 2001). Online students also need to access student support resources, such as library services, counseling, tutoring, or disability services, many of which are not easily delivered remotely (Jaggars, 2011). Because the pandemic dictated the use of online courses for some students with no intention of learning online, the need to train students in these skills to succeed in online learning may be heightened in the current crisis.

\section{Online Instructional Demands and Faculty Training}

The unique features of online education imply that effective pedagogies in face-to-face settings may not readily transfer to online settings. For instance, compared with face-to-face instruction, online teaching demands greater instructor technological proficiency. Instructors must understand how to navigate online learning management systems (such as Canvas), be familiar with various technological tools, and be capable of integrating multimedia into content delivery (Lockyer \& Bennett, 2006; Kearney \& Maher, 2013). Yet, a recent study conducted in the wake of COVID-19 found that many college instructors were not equipped with the technological skills to teach in online settings (Brooks \& Grajek, 2020). To enable faculty to harness technological tools effectively, it is important that instructors receive guidance and support on what tools to use, why to use these tools, and how to use them.

Similarly, the literature reviewed above suggests that online learning is highly learnerautonomous, requiring stronger self-direction and self-discipline to succeed (Rovai, 2003; Guglielmino \& Guglielmino, 2003). Thoughtful online course design can help scaffold this process. Successful online instructors provide clear course structure and guidance, including offering navigational documents and instruction that explicitly guide students in terms of where to go, what to do next, and how to succeed in online learning (Grandzol, 2006).

Finally, online courses face challenges in that nonverbal and relational cues-common in face-to-face communication - are generally missing, which may foster feelings of isolation and depress engagement (Huguet et al., 2001; Moore, 1989; Nissenbaum \& Walker, 1998). This requires instructors to facilitate interpersonal interaction and foster social presence more visibly and intentionally in online learning (Pacansky-Brock et al., 2020; Richardson et al., 2015). Professional training may help new online instructors learn to promote interaction, presence, and engagement in online courses (McCarthy \& Samors, 2009; Shepherd et al., 2016; Varvel, 2007). Because online teaching demands a unique set of skills, it is important that institutions train instructors compelled to shift courses online in these domains to promote student success during emergency remote instruction.

Though formal training may help instructors adapt to the unique pedagogical and relational features of online teaching, instructors also may benefit from informal support networks for support during a transition to online learning. In particular, instructors can benefit from the experiences of colleagues who have previously taught the same class online (Cooper et al., 2020). Institutions where a greater share of courses have previously been taught online may therefore see easier transitions for instructors new to teaching online. 


\section{Institutional Resources Affecting Readiness to Switch to Online Learning}

Institutional factors may also affect conditions for online learning. Previous studies have shown that larger institutions in urban areas with higher percentages of white students (Cox, 2005; Githens et al., 2014), institutions with administrative commitment to funding and coordinating necessary structures around student and faculty support (Cox, 2005; Johnson \& Berge, 2012; Muljana \& Luo, 2019; Thistoll \& Yates, 2016), and technological infrastructure and support (Cox, 2005; Lee, 2008; Muljana \& Luo, 2019) tend to more easily transition to an online learning environment. Other literature finds that institutions that have built trust between faculty and administration (Martins \& Nunes, 2016) and connections to other colleges for resource-sharing (Cox, 2005; Githens et al., 2014; Muljana \& Luo, 2019) lean towards better outcomes when it comes to online course adoption.

\section{Conceptual Model}

Guided by the theories and empirical evidence cited above, we posited a model in which pre-COVID institutional characteristics, pre-COVID distance education ("DE") learning resources, emergency responses during the pandemic, and fall readiness are related (Figure 1). Colleges' readiness for DE in the fall was modeled as a function of their emergency responses, their pre-COVID DE learning resources, and pre-COVID institutional characteristics. Emergency efforts were posited to rely on pre-COVID characteristics of institutions; for instance, colleges with more established faculty training programs may have had an easier time scaling existing training to reach newly-online faculty. Finally, pre-COVID DE resources were posited to be related to pre-COVID institutional characteristics like organizational ties to other colleges for resource-sharing, or student demographics.

\section{Figure 1.}

Conceptual Model of Study.

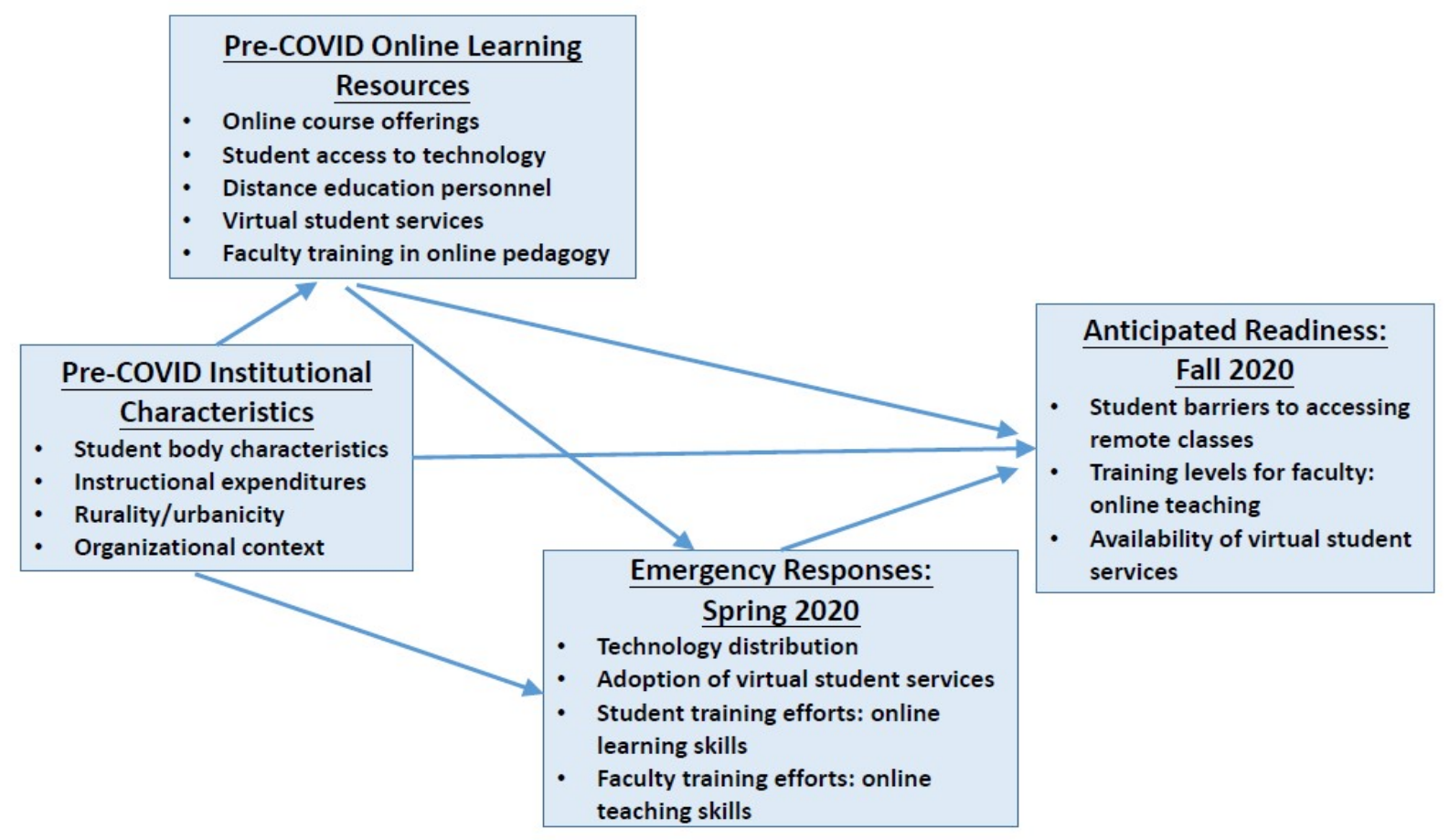


To explore this model, we collected information on all four sets of measures from community colleges in California. We focused on community colleges for several reasons. First, online learning decrements compared to face-to-face settings seem to be especially pronounced in broad access institutions like community colleges (Xu \& Jaggars, 2013; Bettinger et al., 2017; Hart et al., 2018). This performance differential suggests a greater need in these settings to support successful online learning and teaching. To the extent that this need is driven by resource constraints like less reliable access to technology, community college readiness for DE in pandemic conditions may be particularly important to understand.

On the other hand, community colleges may have some advantages in transitioning to emergency online learning because DE was more prevalent in broad-access institutions preCOVID (Allen \& Seaman, 2014; Chen, 2018). This has led some community college systems to invest in improving DE. For instance, in 2014 the California Community Colleges Chancellor's Office (CCCCO) funded the creation of the California Virtual Campus-Online Education Initiative (CVC-OEI), a collaborative effort to promote high-quality online learning opportunities systemwide by providing supports for online student learning and offering resources to improve online teaching (Johnson et al., 2015). The widespread use of DE in community colleges may therefore smooth the transition for this sector.

Using the information collected, we addressed three research questions:

1. What were the average levels of pre-COVID campus DE resources that could be tapped to ease the transition to emergency remote instruction, and how did these resources vary across the CCC system based on institutional characteristics?

2. What types of emergency responses did campuses launch to address the pandemic, and how did these responses vary across the CCC system based on institutional characteristics and pre-COVID DE resources?

3. What are the average levels of reported readiness for emergency remote instruction in fall 2020, and how does readiness vary across the CCC system based on institutional characteristics, pre-COVID DE resources, and strength of emergency responses to COVID-19?

\section{Methods}

\section{Data Sources}

We drew on three main data sources to answer these research questions: (a) a novel survey of DE leaders that we conducted to elicit information on institutional practices related to online teaching and learning, both before and during COVID-19; (b) survey data from the Integrated Postsecondary Education Data System (IPEDS) to characterize broader institutional contexts and financial resources; and (c) administrative data from the CCCCO to characterize pre-COVID online course offerings.

COVID-19 Distance Education Leaders Survey. Informed by literature on online teaching and learning, the research team developed the COVID-19 Distance Education Leaders Survey (CDELS) to collect information on colleges' pre-COVID DE resources, emergency responses to COVID-19, and readiness for the fall 2020 term. After initial survey development, the research team conducted pilot administrations with DE leaders at two colleges to ensure that 
questions were clear and capturing the relevant aspects of each domain. Feedback was incorporated to refine the instruments.

Surveys were administered in September and October 2020 to DE leaders throughout the California Community College system. DE leaders-generally DE Coordinators, but sometimes leaders in other roles such as DE deans or faculty chairs of DE committees, depending on leadership structures at each college-were identified through community college websites. We used several strategies to improve response rates, including announcing the survey at a systemwide monthly meeting of DE leaders, sending reminder emails, and directly calling nonresponding campuses. At some campuses where DE leadership roles were shared (e.g., co-DE coordinators), we sent invitations to both leaders. In total, we sent 133 invitations to leaders representing 114 colleges with on-ground campus classes as of spring 2019. We received 47 responses from 45 unique colleges, for a response rate of nearly $40 \%$. Comparisons of the characteristics of responding colleges to those of non-responding colleges revealed no significant differences (Online Appendix Table OA1).

Other data sources. We drew several institutional variables from IPEDS, an annual survey of postsecondary institutions conducted by the National Center for Education Statistics (U.S. Department of Education, 2018). The survey collects aggregate data on college characteristics such as enrollment numbers and college demographics, as well as financial data (e.g., on revenues and expenditures). We used data from the 2017-18 academic year, because some measures we used were unavailable as of 2018-19. We also drew on administrative data from the CCCCO to capture pre-COVID online course offerings and to determine which colleges belonged to multi-college districts. We used data from the 2018-19 academic year to get the most up-to-date view of online education in the system prior to the COVID-19 crisis. Finally, we drew on a list of the current set of colleges that belong to the California Virtual College-Online Education Initiative consortium from the CVC-OEI webpage.

\section{Measures}

Measures are described briefly below; we provide more detail on construction of these measures in Online Appendix Table OA2.

Pre-COVID institutional characteristics. We used IPEDS data to capture several measures of preexisting institutional characteristics. We included two measures of student socioeconomic status: the share of first-time undergraduate students using Pell grants ("Share Pell [\%]"), and the share of students from racial/ethnic groups traditionally under-represented in college ("Share URM [\%]").

We also included other institutional characteristics that may relate to DE resources. For instance, we included per-pupil expenditures on instruction (which is likely to directly affect teaching and learning resources at an institution); unduplicated head count (which may affect the ease of scaling up different responses to COVID-19); and indicators for campus rurality or urbanicity (suburban location serves as the reference category; urbanicity may affect factors like connectivity that determine access to online courses).

We used CCCCO data to determine which schools belonged to multi-college districts, and a published list of members to determine which schools belonged to the CVC-OEI consortium. While the CVC-OEI leads systemwide efforts on online education, colleges that opt for additional engagement by joining the consortium receive additional supports from the CVC-OEI (such as 
access to virtual tutoring services), and agree to work towards targets such as meeting standards of online course quality. Both of these variables potentially capture colleges' access to external resources that they could draw on in formulating their responses.

Pre-COVID distance education resources. We used five main measures to capture the level of pre-COVID DE resources that could be mobilized as campuses transitioned to emergency remote instruction. The first is the share of courses at a given college that had at least one section offered online in the 2018-19 school year ("Courses with Any Online Section").

All other measures are drawn from the CDELS survey. The second measure captures DE leaders' estimates of the share of students in spring 2020 who would have lacked necessary technology to access online classes prior to any campus efforts to distribute technology ("Share: Tech Access Barriers, Spring"). The third is the number of reported personnel devoted to DE, relative to student body size ("DE Personnel per 1000 Students").

The fourth measure aggregates several individual items in which DE leaders estimated the percentage of faculty teaching online who were trained in eight different areas of skill relevant to online learning (Canvas skills, fostering student-instructor interaction, fostering student-student interaction, course organization, accessibility, personalizing/humanizing instruction, equity, and Zoom skills) prior to COVID-19. For example, while our conversations with campus distance education leaders suggest that most colleges offered Canvas training to faculty teaching online, in some colleges less than $10 \%$ of faculty teaching online were estimated to already have such training in spring 2020, while in other colleges $100 \%$ were estimated to have Canvas training. We first standardized the estimated percentage trained for each skill (i.e., each skill item had a mean of zero and standard deviation of 1). We then averaged the standardized values across the eight areas for each institution and restandardized the aggregate measure. This aggregated measure ("Pre-COVID Faculty Training Scale") captures the notion that campuses with more trained faculty may have (a) had training programs in place that they could scale up to train new online faculty, and (b) had a well-trained body of faculty who could be more readily tapped to help their colleagues transition online.

The final measure is whether campuses previously had both online tutoring and counseling options offered virtually ("Virtual Tutoring and Counseling Available Pre-COVID"). Tutoring options could include virtual appointments through the home campus or through third-party providers such as NetTutor. When respondents indicated that they were unsure about the availability of these services, responses were set to missing.

To reduce the dimensionality of these measures, we combined the five measures into a single indicator of "higher" versus "lower" levels of resources, using agglomerative hierarchical cluster analysis. Hierarchical cluster analysis groups individual items into larger clusters by measuring the distance between observations in terms of the index variables specified, and then grouping together observations that resemble each other. To put index items on similar scales, we standardized all of the continuous measures. To preserve observations with missing values, and for the cluster analysis only, we imputed the sample mean to any missing variables. Because our index measures included both dichotomous and continuous measures, we used Gower's (1971) dissimilarity measure, which is better suited than other dissimilarity measures to accommodate both binary and continuous data.

The dendrogram for this analysis (Online Appendix Figure OA1) shows the cluster structure from the hierarchical cluster procedure using a complete linkage method. Cluster 
groupings were not sensitive to using average linking procedures. Note that the greatest dissimilarity displayed is a single school (random ID number of 35 on the chart) that is dissimilar from all other institutions, so we excluded this school from the cluster construction. We describe the interpretation of the cluster analysis in the Results section.

Emergency responses. We focused on four main ways that colleges acted to support students and instructors in the transition to emergency remote instruction. First, we characterized technology distribution efforts based on the reported number of four different types of technology that were distributed to students in the wake of the COVID-19 crisis, including personal computers (laptops/Chromebooks), hotspots, webcams, and headsets. This yielded a scale ("Number of Device Types Distributed") that ranged from 0-4.

Second, we captured colleges' efforts to provide training to students in eight different domains of skill useful in remote learning: Canvas, Zoom, interaction in online classes, study skills for online classes, accessing student services remotely, navigating technical requirements to connect to online classes, using particular devices (e.g., Chromebooks) or using particular products (e.g., Proctorio). We again generated a count of the number of different skills for which colleges offered training ("Number of Domains of Student Skill Training"), yielding a scale ranging from $0-8$.

Third, we characterized institutions' efforts to expand student services by examining whether colleges newly offered any online tutoring or counseling since the onset of the COVID19 crisis ("Adopted Virtual Tutoring or Counseling"). Thus, colleges that either had prior online services in place, or did not offer any online services as of fall 2020, received values of 0 on this measure.

Finally, we captured institutions' efforts to promote online course quality through professional training by examining whether campuses offered each of seven different approaches to training newly-online faculty (synchronous training sessions by campus personnel; one-on-one consultations with DE personnel; one-on-one consultations with instructional designers; one-oneone consultations with faculty mentors; asynchronous tutorials created by campus personnel; asynchronous tutorials offered by the CVC-OEI; or asynchronous tutorials offered through other outside entities). This generated a scale ("Number of Emergency Faculty Training Approaches") ranging from $0-7$.

Fall readiness. We characterized readiness in three main domains. The first domain captured the share of students that CDELS respondents estimated would still face barriers in accessing virtual classes in fall 2020 due to issues like lack of devices or connectivity ("Share: Tech Access Barriers, Spring [\%]").

The second measure captured the share of faculty that respondents estimated would be trained in each of the eight online teaching skills for the fall 2020 term ("Fall Faculty Training Scale [Std.]"). For example, at one college, only $10 \%$ of faculty were estimated to have Zoom training at the beginning of spring 2020, and that percentage grew to $85 \%$ by fall 2020 . As we did to capture pre-COVID training levels, we standardized each item, averaged these standardized variables for each institution, and restandardized the aggregate measure so that it had a mean of 0 and standard deviation of 1 .

The third measure captured whether colleges reported the availability of both virtual tutoring and counseling by the fall 2020 term ("Virtual Tutoring and Counseling Available: Fall"). 
A value of 1 indicated that colleges had both tutoring and counseling available virtually, while campuses with a value of 0 were missing virtual options for one or both. Again, when respondents marked that they were unsure, this value was set to missing.

Multiple responses. For two colleges, we received responses from two respondents from the same college (e.g., where DE leadership was shared between two faculty members). To ensure that all campuses were represented only once, we combined information from both respondents. For continuous measures, we averaged the responses. Because binary measures tended to capture the presence or absence of particular efforts, we took the higher of the two values based on the logic that respondents are more likely to underestimate efforts (e.g., underreporting the distribution of hotspots due to lack of knowledge) than overestimate them (assuming that hotspots were being distributed when they were not). Results were qualitatively similar if we dropped responses from the duplicated colleges.

\section{Models}

We used simple descriptive and regression analyses to explore relationships between measures of fall readiness, emergency responses to COVID-19, pre-COVID DE resources, and institutional characteristics. For instance, we fit models that treat emergency response variables Response $_{s}$ as a function of the pre-COVID resource cluster measure ResourceCluster $_{s}$ and a vector of institutional characteristics InstChar, as below:

$$
\text { Response }_{s}=\alpha+\beta \text { ResourceCluster }_{s}+\gamma \text { InstChar }_{s}+\varepsilon_{s}
$$

where $\varepsilon_{\mathrm{s}}$ represents an independent and identically distributed error term.

For our final set of results, we fitted path analysis models to capture the direct and indirect relationships between fall readiness measures and the pre-COVID DE resources, emergency response variables, and institutional variables most closely related to the outcome of interest. Because the covariates included were selected based on our prior results, we provide more detail on those models in the Results section.

\section{Results}

\section{Research Question 1: Pre-COVID DE Resources}

Colleges had considerable variation in readiness for online instruction prior to the onset of COVID-19. The summary statistics presented in Table 1 show that the average share of courses pre-COVID with at least one section taught online was about $21 \%$ across respondent colleges with a relatively large standard deviation $(\mathrm{SD}=10)$.

Respondents estimated that nearly half (45\%) of students in spring 2020 faced technology barriers in accessing remote classes, due to issues such as limited access to devices or connectivity. Yet, there was noticeable variation across institutions. The 25th and 75th percentile values indicated that one quarter of institutions estimated that less than $29 \%$ of their students would face barriers, while another quarter estimated difficulty for more than $60 \%$.

In terms of resources to support online students, campuses averaged just one FTE position dedicated to DE for every 2,000 full-time students. Over $60 \%$ of campuses provided virtual access to both tutoring and counseling prior to the onset of COVID-19. In practice, the variation in this 
measure was driven by variability in access to virtual counseling since all respondent colleges had some form of tutoring available virtually.

Since we standardized the variables that measure the number of types of professional training offered to faculty, the faculty training scale has a mean of 0 and a standard deviation of 1 by construction. To provide additional context, Panel B presents the raw measures (proportion of faculty trained) in each of the eight skills. These measures also suggested noticeable variations in the prevalence of trained faculty: over half $(58 \%)$ of online faculty had training in use of Canvas pre-COVID, with substantial numbers also trained in skills like fostering instructor-student (46\%) or student-student $(40 \%)$ interactions. In contrast, relatively few had prior training in humanizing instruction (27\%), equity (25\%), or the use of Zoom (24\%).

Columns 5 and 6 present descriptive statistics for colleges based on the two clusters identified by our hierarchical cluster analysis. The pattern of results suggests that the 14 colleges placed in Cluster 1 (Column 5) had fewer pre-COVID DE resources compared to the 30 colleges placed in Cluster 2 (Column 6), across several-but not all-dimensions. Most notably, all colleges in the higher-resource group offered virtual tutoring and counseling pre-COVID, while all colleges in the lower-resource cluster lacked at least one of these virtual student services. The higher-resource group also has higher scores on the pre-COVID online faculty training scale, as well as in each of the individual online teaching skills. 
Table 1

Pre-COVID DE Resources, By Cluster

\begin{tabular}{|c|c|c|c|c|c|c|}
\hline & \multicolumn{4}{|c|}{ Full Sample } & \multicolumn{2}{|c|}{$\begin{array}{c}\text { Cluster Comparison } \\
\text { (means) }\end{array}$} \\
\hline & $\begin{array}{c}\text { Mean } \\
(1)\end{array}$ & $\begin{array}{l}\text { SD } \\
(2)\end{array}$ & $\begin{array}{c}25^{\text {th }} \\
\text { Pctile } \\
(3)\end{array}$ & $\begin{array}{c}75^{\text {th }} \\
\text { Pctile } \\
(4)\end{array}$ & $\begin{array}{c}\text { Cluster 1: } \\
\text { Lower } \\
\text { Resources } \\
(5)\end{array}$ & $\begin{array}{l}\text { Cluster 2: } \\
\text { Higher } \\
\text { Resources } \\
(6)\end{array}$ \\
\hline \multicolumn{7}{|l|}{ Panel A. Main Measures } \\
\hline $\begin{array}{l}\text { Share Courses with Any } \\
\text { Section Online }(\%)\end{array}$ & 21 & 10 & 16 & 25 & 20 & 20 \\
\hline $\begin{array}{l}\text { Share: Tech Access Barriers, } \\
\quad \text { Spring }(\%)\end{array}$ & 45 & 24 & 29 & 60 & 45 & 45 \\
\hline $\begin{array}{l}\text { DE Personnel per } 1000 \\
\text { Students }\end{array}$ & 0.43 & 0.58 & 0.19 & 0.41 & 0.39 & 0.33 \\
\hline $\begin{array}{l}\text { Virtual Tutoring and } \\
\text { Counseling Pre-COVID }\end{array}$ & 0.62 & 0.49 & 0.00 & 1.00 & 0.00 & 1.00 \\
\hline $\begin{array}{l}\text { Pre-COVID Faculty Training } \\
\quad \text { Scale (Std.) }\end{array}$ & 0.00 & 1.00 & -0.75 & 0.63 & -0.38 & 0.15 \\
\hline \multicolumn{7}{|c|}{ Panel B. Component Measures of Faculty Training Scale. } \\
\hline \multicolumn{7}{|c|}{ Share Pre-COVID Online Faculty Trained In: } \\
\hline Canvas & 58 & 31 & 35 & 82 & 50 & 61 \\
\hline Student-Instructor Interaction & 46 & 34 & 20 & 76 & 32 & 52 \\
\hline Student-Student Interaction & 40 & 33 & 18 & 71 & 29 & 44 \\
\hline Class Organization & 39 & 32 & 15 & 61 & 31 & 41 \\
\hline Accessibility & 37 & 33 & 10 & 50 & 30 & 38 \\
\hline $\begin{array}{l}\text { Personalizing/Humanizing } \\
\text { Instruction }\end{array}$ & 27 & 26 & 10 & 33 & 16 & 33 \\
\hline Equity & 25 & 26 & 7 & 29 & 18 & 27 \\
\hline Zoom & 24 & 26 & 9 & 25 & 16 & 28 \\
\hline Sample Size & 45 & & & & 14 & 30 \\
\hline
\end{tabular}

Estimates are unweighted. $* * * p<.01, * *, p<.05, * \mathrm{p}<.10$. The cluster sample excludes one respondent institution that did not fit well into either cluster.

While the patterns around faculty training and virtual student services favored the higherresource groups, these differences should be viewed as suggestive for two reasons. First, the "lower-resource" colleges reported similar results on shares of courses offering at least one section online, shares of students facing access barriers, and DE-personnel-to-student ratios. Second, the only statistically significant difference among the main cluster components was on the availability of virtual tutoring and counseling, though the difference in the pre-COVID faculty training scale approached marginal significance $(\mathrm{p}=0.109)$ and several between-cluster differences in individual skill domains reached statistical significance. While we caution against over-interpreting our clusters, we conducted exploratory multiple regression analyses to determine whether institutional characteristics systematically predicted placement in the higher-resource cluster (Table 2). 
We found relatively few relationships between the likelihood of being in the higherresource cluster and most institutional characteristics, with the notable exception that CVC-OEI consortium members were marginally more likely to be in the higher-resource group. Analyses using each component pre-COVID DE resource as the outcome in turn (Columns 2-6) suggested that this is primarily because CVC-OEI members were more likely to have a fully-online suite of student services available pre-COVID. Prior membership in the consortium therefore may have put colleges in a better position to meet the crisis, particularly from a student services perspective.

\section{Table 2}

Relationship between Pre-COVID DE Resource Cluster and Pre-COVID Demographic and Institutional Characteristics

\begin{tabular}{lcccccc}
\hline & & $\%$ & $\%$ & & Virt. & Fac. \\
& Higher & Student & Courses, & DE FTE & Tutor. & Train. \\
& Resource & Access & 1+ Sect. & Per 1000 & and & Scale \\
& Cluster & Barriers & Online & Students & Counsel. & $\begin{array}{c}\text { (Std.) } \\
(6)\end{array}$ \\
& $(1)$ & $(2)$ & $(3)$ & $(4)$ & $(5)$ & b/se \\
& b/se & b/se & b/se & b/se & b/se & b/se \\
\hline Student Demographics & & & & & & \\
Share URM (\%) & -0.00 & $1.03 * * *$ & $-0.23 *$ & -0.01 & -0.01 & -0.02 \\
Share Pell (\%) & $(0.01)$ & $(0.29)$ & $(0.12)$ & $(0.01)$ & $(0.01)$ & $(0.01)$ \\
& 0.00 & $-1.07 * * *$ & 0.06 & 0.00 & 0.00 & 0.03 \\
& $(0.01)$ & $(0.36)$ & $(0.15)$ & $(0.01)$ & $(0.01)$ & $(0.02)$ \\
\hline Institutional Characteristics & & & & & & \\
Instr. Exp./FTE (\$1000s) & 0.01 & -0.16 & -1.19 & -0.06 & 0.04 & -0.07 \\
& $(0.04)$ & $(1.94)$ & $(0.83)$ & $(0.06)$ & $(0.05)$ & $(0.09)$ \\
Undup. Head Ct. (1000s) & 0.01 & -0.50 & -0.01 & -0.01 & 0.01 & $0.04 *$ \\
& $(0.01)$ & $(0.46)$ & $(0.19)$ & $(0.01)$ & $(0.01)$ & $(0.02)$ \\
Rural & 0.14 & $39.12 * *$ & -7.17 & 0.19 & -0.07 & 0.52 \\
& $(0.33)$ & $(14.49)$ & $(6.20)$ & $(0.64)$ & $(0.40)$ & $(0.70)$ \\
Urban & 0.17 & 3.66 & 2.58 & 0.09 & 0.09 & 0.03 \\
& $(0.18)$ & $(8.03)$ & $(3.43)$ & $(0.25)$ & $(0.20)$ & $(0.39)$ \\
Multi-College District & -0.09 & 9.49 & 2.72 & 0.11 & -0.10 & 0.05 \\
CVC Consortium College & $(0.18)$ & $(8.31)$ & $(3.53)$ & $(0.27)$ & $(0.21)$ & $(0.40)$ \\
& $0.28 *$ & -5.38 & 3.63 & 0.06 & $0.41 * *$ & -0.14 \\
Constant & $(0.16)$ & $(7.16)$ & $(3.02)$ & $(0.22)$ & $(0.19)$ & $(0.34)$ \\
& $1.39 * *$ & 36.64 & $34.99 * * *$ & 1.09 & 0.16 & -0.34 \\
& $(0.62)$ & $(27.65)$ & $(11.70)$ & $(0.86)$ & $(0.67)$ & $(1.32)$ \\
& 44 & 44 & 45 & 39 & 37 & 41 \\
\hline
\end{tabular}

Coefficients (st. error). Estimates are unweighted. ${ }^{* *} \mathrm{p}<.01,{ }^{* *}, \mathrm{p}<.05,{ }^{*} \mathrm{p}<.10$. URM $=$ Underrepresented minorities. Pell receipt captures share of first-time undergraduates using Pell. 


\section{Research Question 2: Emergency Responses to COVID-19}

Our next research question addressed the prevalence of different emergency responses to COVID-19 and their connection to prior resource levels and other institutional characteristics. Domains of emergency responses included provision of technology to students, adoption of new virtual student services, offering student skill training in different domains useful to online learning, and approaches to training faculty. Descriptive statistics of these measures are presented in Table 3. Panel A presents the main four domains of responses; Panel B presents component items under each domain.

Table 3

Emergency Instructional Responses

\begin{tabular}{|c|c|c|c|c|c|c|}
\hline & \multirow[b]{3}{*}{$\begin{array}{l}\text { Mean } \\
(1)\end{array}$} & \multirow[b]{3}{*}{$\begin{array}{l}\text { SD } \\
(2)\end{array}$} & \multirow{3}{*}{$\begin{array}{l}25^{\text {th }} \\
\text { Pctile } \\
\text { (3) }\end{array}$} & \multirow{3}{*}{$\begin{array}{l}75^{\text {th }} \\
\text { Pctile } \\
\text { (4) }\end{array}$} & \multicolumn{2}{|c|}{ Mean } \\
\hline & & & & & Low & High \\
\hline & & & & & $\begin{array}{l}\text { Res. } \\
(5)\end{array}$ & $\begin{array}{l}\text { Res. } \\
(6)\end{array}$ \\
\hline \multicolumn{7}{|l|}{ Panel A. Main Measures } \\
\hline Number of Device Types Distributed & 2.07 & 0.99 & 1.00 & 2.00 & 1.86 & 2.10 \\
\hline Adopted Virtual Tutoring or Counseling & 0.38 & 0.49 & 0.00 & 1.00 & 1.00 & 0.04 \\
\hline Num. Domains of Student Skill Trainings & 4.16 & 2.57 & 2.00 & 6.00 & 2.93 & 4.69 \\
\hline $\begin{array}{l}\text { Num. Emergency Faculty Training } \\
\text { Approaches }\end{array}$ & 4.85 & 1.58 & 4.00 & 6.00 & 4.07 & 5.12 \\
\hline \multicolumn{7}{|l|}{ Panel B. Additional Detail on Scale Measures } \\
\hline \multicolumn{7}{|l|}{ Devices Distributed, by Type } \\
\hline Personal Computing Device & 1.00 & 0.00 & 1.00 & 1.00 & 1.00 & 1.00 \\
\hline Hotspots & 0.70 & 0.46 & 0.00 & 1.00 & 0.57 & 0.76 \\
\hline Headsets & 0.18 & 0.39 & 0.00 & 0.00 & 0.14 & 0.17 \\
\hline Webcams & 0.23 & 0.42 & 0.00 & 0.00 & 0.14 & 0.24 \\
\hline \multicolumn{7}{|l|}{ Student Skill Training Offered, by Skill } \\
\hline Canvas & 0.75 & 0.44 & 0.50 & 1.00 & 0.57 & 0.83 \\
\hline Access Stud. Services & 0.70 & 0.46 & 0.00 & 1.00 & 0.57 & 0.76 \\
\hline Communication Skills & 0.61 & 0.49 & 0.00 & 1.00 & 0.50 & 0.69 \\
\hline Zoom & 0.61 & 0.49 & 0.00 & 1.00 & 0.50 & 0.66 \\
\hline Study Skills & 0.57 & 0.50 & 0.00 & 1.00 & 0.29 & 0.69 \\
\hline Technical Requirements & 0.45 & 0.50 & 0.00 & 1.00 & 0.29 & 0.52 \\
\hline Products & 0.25 & 0.44 & 0.00 & 0.50 & 0.14 & 0.28 \\
\hline Devices & 0.20 & 0.41 & 0.00 & 0.00 & 0.07 & 0.28 \\
\hline \multicolumn{7}{|c|}{ Approaches to Emergency Faculty Training, by Type } \\
\hline Synchronous Trainings & 0.88 & 0.33 & 1.00 & 1.00 & 0.79 & 0.96 \\
\hline Tutorials: Through Campus & 0.85 & 0.36 & 1.00 & 1.00 & 0.79 & 0.88 \\
\hline Consult with DE Personnel & 0.80 & 0.40 & 1.00 & 1.00 & 0.79 & 0.81 \\
\hline Tutorials: CVC & 0.76 & 0.43 & 1.00 & 1.00 & 0.71 & 0.77 \\
\hline Consult with Peer Mentors & 0.66 & 0.48 & 0.00 & 1.00 & 0.57 & 0.69 \\
\hline Tutorials: Outside Provider & 0.42 & 0.50 & 0.00 & 1.00 & 0.29 & 0.46 \\
\hline Consult with Instructional Designers & 0.41 & 0.50 & 0.00 & 1.00 & 0.14 & 0.54 \\
\hline Sample Size & 45 & & & & 14 & 30 \\
\hline
\end{tabular}


Estimates are unweighted. ${ }^{* * *} \mathrm{p}<.01, * *, \mathrm{p}<.05, * \mathrm{p}<.10$.

On average, colleges in our sample distributed two types of devices. Further breakdowns of specific types of devices distributed revealed substantial variations: All colleges distributed personal computing devices (laptops or Chromebooks) and $70 \%$ distributed hotspots. In contrast, less than a quarter distributed other peripherals (headsets or webcams). A little over a third of respondent colleges reported implementing newly adopted virtual counseling or tutoring services. Because virtual tutoring was already widely available pre-COVID, this variable effectively captured adoption of virtual counseling services.

Colleges also provided several training opportunities to students and faculty to prepare for online teaching and learning. Institutions on average offered four different types of training to students and used close to five approaches in faculty professional training. In terms of student skills, the vast majority of colleges (75\%) offered training on Canvas and accessing student services $(70 \%)$. Majorities also offered training on how to communicate effectively in online classes (61\%), using Zoom (61\%), and study skills important to online success (57\%). In contrast, purely technical training was less common; slightly less than half offered training on technical requirements and only about a quarter offered training on using specific software products or devices. Taken together, these descriptive statistics suggested that colleges attended to a variety of skills conducive to successful online learning to support students in remote instruction, although there were noticeable variations in the prevalence of specific training provided.

With respect to approaches to faculty training, the vast majority of colleges offered synchronous trainings (e.g., face-to-face or over Zoom, 88\%), asynchronous tutorials created by campus staff (85\%), and one-on-one consultation with DE personnel (80\%). Most campuses also offered links to tutorials through the CVC-OEI (76\%), and organized peer mentor networks to help new online instructors $(66 \%)$. Fewer colleges offered consultation with instructional designers (41\%); open-ended survey comments suggest that this may be because some colleges lacked personnel in this role.

Responses varied depending on pre-COVID levels of DE resources. This is demonstrated both in the comparisons between Columns 5 and 6 of Table 3, and in Table 4. Panel A of Table 4 presents bivariate relationships between the four emergency response variables and the level of pre-COVID DE resources (measured as whether a college belongs to the higher-DE resource cluster). Since colleges in the higher-resource cluster all provided online student services prior to the COVID, it is unsurprising that colleges in the lower-resource cluster were more likely to newly adopt virtual student services in the wake of the pandemic. Colleges with higher pre-COVID DE resources offered training in a greater number of student online learning skills (Column 3 ) and a greater number of different approaches to faculty training in the wake of the COVID (Column 4). All of these bivariate relationships persisted as we added institutional characteristics as controls in the model (Panel B), although the magnitudes of the coefficients attenuated slightly and the coefficient for the student training variable dropped to marginal significance.

In short, all colleges responded to the emergency actively, though there were substantial variations in the level and dimensions of these responses. In particular, institutions with more preCOVID DE resources also provided higher levels of training to students and faculty in the wake of the COVID-19, while lower-resourced institutions adopted novel virtual student services. 


\section{Table 4}

Relationship between Pre-COVID DE Resource Cluster and Pre-COVID Demographic and Institutional Characteristics.

\begin{tabular}{lcccc}
\hline & 1 & 2 & 3 & 4 \\
& $\begin{array}{c}\text { Num. } \\
\text { Device } \\
\text { Types } \\
\text { Distributed } \\
\text { b/se }\end{array}$ & $\begin{array}{c}\text { Adopted } \\
\text { Virtual } \\
\text { Tutor. or } \\
\text { Counsel. } \\
\text { b/se }\end{array}$ & $\begin{array}{c}\text { Num. } \\
\text { Domains } \\
\text { Stud. Skill } \\
\text { Trainings } \\
\text { b/se }\end{array}$ & $\begin{array}{c}\text { Num. } \\
\text { Approaches } \\
\text { to Emerg. } \\
\text { Fac. Training } \\
\text { b/se }\end{array}$ \\
\hline Panel A. Bivariate Relationships & & & & \\
Higher Pre-COVID DE Resources & 0.24 & $-0.96^{* * *}$ & $1.76^{* *}$ & $1.04^{*}$ \\
& $(0.31)$ & $(0.05)$ & $(0.81)$ & $(0.52)$ \\
Constant & $1.86^{* * *}$ & $1.00^{* * *}$ & $2.93^{* * *}$ & $4.07^{* * *}$ \\
& $(0.26)$ & $(0.04)$ & $(0.66)$ & $(0.42)$ \\
\hline Panel B. With Institutional Characteristic Controls & & & \\
Higher Pre-COVID DE Resources & 0.41 & $-0.91^{* * *}$ & $1.68^{*}$ & $0.81^{*}$ \\
& $(0.33)$ & $(0.06)$ & $(0.92)$ & $(0.46)$ \\
Student Demographic Characteristics & & & & \\
Share URM (\%) & 0.00 & 0.00 & 0.02 & $-0.06^{* * *}$ \\
Share Pell (\%) & $(0.01)$ & $(0.00)$ & $(0.04)$ & $(0.02)$ \\
& -0.00 & -0.00 & -0.07 & 0.02 \\
Institutional Characteristics & $(0.02)$ & $(0.00)$ & $(0.04)$ & $(0.02)$ \\
Instruct. Expense/FTE (\$1000) & -0.05 & -0.02 & -0.38 & 0.07 \\
& $(0.09)$ & $(0.02)$ & $(0.24)$ & $(0.12)$ \\
Undupl. Head Count (1000) & $-0.06^{* * *}$ & -0.01 & -0.02 & 0.01 \\
& $(0.02)$ & $(0.00)$ & $(0.06)$ & $(0.03)$ \\
Rural & -0.91 & -0.01 & 1.94 & $-2.51^{* *}$ \\
Urban & $(0.64)$ & $(0.13)$ & $(1.79)$ & $(0.91)$ \\
Multi-College District & -0.35 & 0.05 & 0.86 & 0.61 \\
& $(0.36)$ & $(0.07)$ & $(1.00)$ & $(0.51)$ \\
CVC Consortium College & 0.06 & 0.00 & -0.83 & 0.15 \\
Constant & $(0.36)$ & $(0.07)$ & $(1.02)$ & $(0.52)$ \\
& 0.07 & $-0.11^{*}$ & -0.34 & 0.48 \\
N & $(0.32)$ & $(0.06)$ & $(0.92)$ & $(0.46)$ \\
\hline Con & $3.05^{* *}$ & $1.13^{* * *}$ & $7.61^{* *}$ & $6.12^{* * *}$ \\
& $(1.20)$ & $(0.22)$ & $(3.42)$ & $(1.72)$ \\
\hline 44 & 39 & 43 & 39 \\
\hline
\end{tabular}

Coefficients (st. error). Estimates are unweighted. ${ }^{* *} \mathrm{p}<.01,{ }^{* *}, \mathrm{p}<.05,{ }^{*} \mathrm{p}<.10$. URM $=$ Underrepresented minorities. Pell receipt captures share of first-time undergraduates using Pell. 


\section{Research Question 3: Projections of Fall Readiness}

Our final research question sought to describe fall 2020 readiness measures and relate them to pre-COVID resource and emergency response variables. Table 5 shows descriptive statistics for fall readiness measures. Colleges still reported substantial student needs for fall: Respondents estimated that on average $30 \%$ of students would still face difficulty accessing remote classes in the fall, with substantial variability across colleges. A quarter of schools estimated that $44 \%$ or more of fall students would face barriers accessing online classes, while another quarter of colleges placed their estimates at $11 \%$ or lower.

Respondents also anticipated that high proportions of faculty members would be trained in various areas of skills for the fall (Panel B). Respondents estimated that $77 \%$ of instructors would be trained on Canvas use, on average, which represented a 33\% improvement compared to the average pre-COVID level of training on Canvas use (58\% of the instructors). In a similar vein, there was a substantial increase in the proportion of faculty trained in every area of skills examined compared with the pre-COVID levels: Fall 2020 training rates for student-instructor interaction, student-student interaction, class organization, accessibility, and Zoom were estimated to be over $50 \%$ on average across colleges.

\section{Table 5}

Descriptive Statistics for Fall Readiness

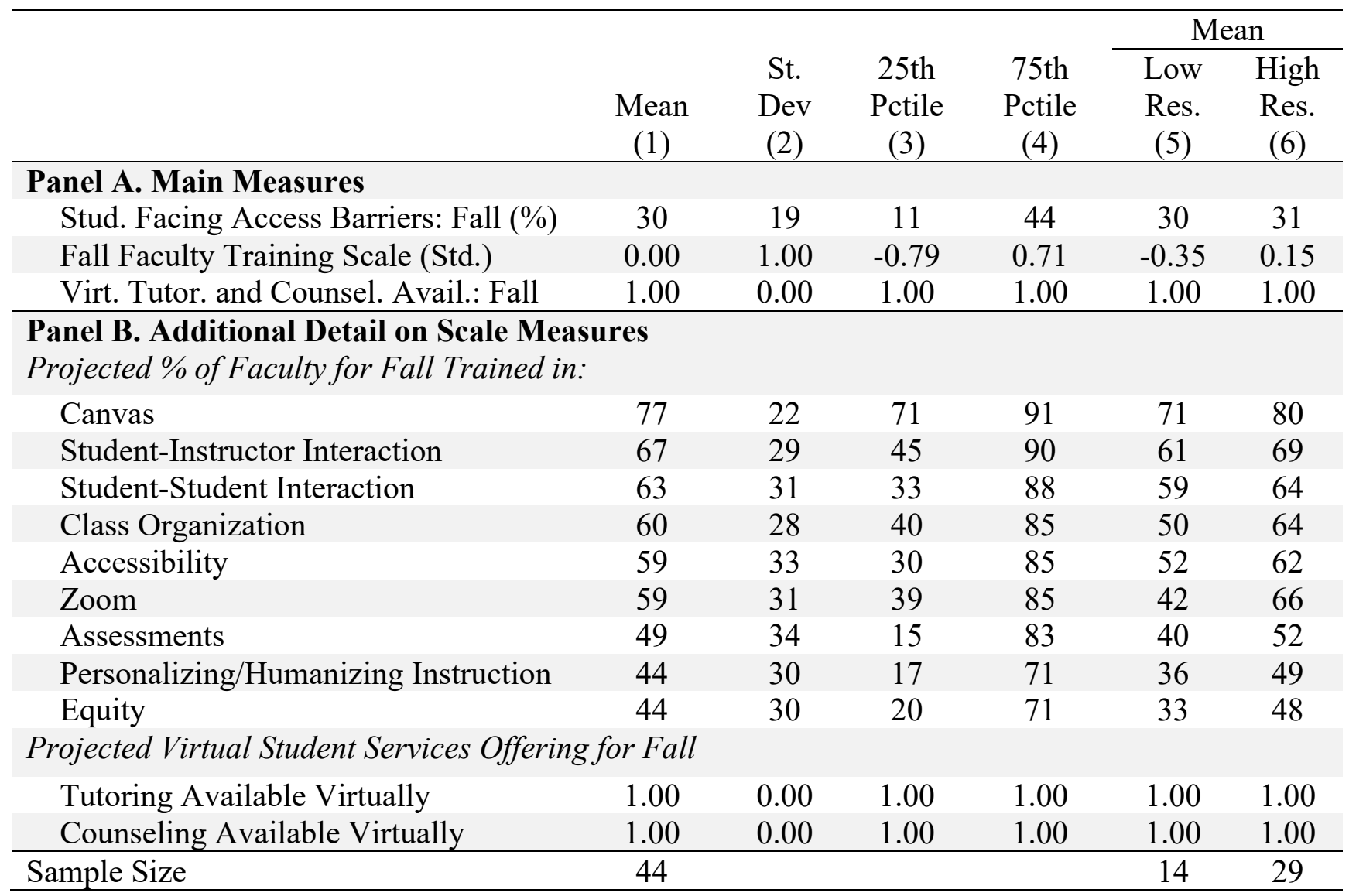

Estimates are unweighted. 
All institutions in our sample expected to offer virtual student services, including both virtual tutoring and counseling, in the fall, resulting in zero variability in this measure.

Finally, we examined whether institutions' fall readiness measures were related to their pre-COVID DE resources and emergency responses. We excluded virtual student service availability as an outcome because there was no variation to support analysis. We fitted path analysis models for the student access barriers and faculty training fall readiness measures, using the pre-COVID DE resource, emergency response measures, and institutional covariates most likely to be related to the fall readiness measures as covariates. We chose institutional covariates that were significantly related to either the pre-COVID DE resource or emergency response variables included (based on Tables 2 and 4). Thus, we modeled fall student barriers to accessing courses as a function of the spring measures of barriers to access, the number of types of technology colleges distributed, the share of students from underrepresented minority groups, share of students receiving Pell, rurality, and unduplicated head count. Fall faculty training levels were modeled as a function of pre-COVID faculty training levels, the number of training approaches used during the crisis, the share of students from under-represented minority groups, rurality, and unduplicated head count. The models were specified and identified prior to estimating the parameters. Paths were posited to follow Figure 1.

We present results for projected share of students facing technical access difficulties in the fall in Figure 2, Panel A, and projected level of faculty training in Panel B. Italicized coefficients are significant at $p<0.10$; bold coefficients are significant at $p<0.05$. Results are also presented in tabular form in Appendix Table OA3, along with statistics of goodness of fit indicating acceptable fit for our models. We do note, however, that our models should be interpreted with considerable caution since our small sample size $(\mathrm{N}=45)$ means that our sample size-to-parameter ratio falls below the suggested threshold of 5:1 (Bentler \& Chou, 1987).

For both outcomes, the strongest predictor of fall readiness measures was-not surprisingly - the spring versions of the same measures, capturing resources in place prior to emergency responses. In both cases, emergency responses were related to fall readiness measures in the expected directions, but in neither case were the associations significant in our fully controlled path analysis models. For instance, a one standard deviation increase in the measure of types of technology distributed was associated with a -0.20 standard deviation change in the share of students anticipated to face barriers to accessing classes in the fall; however, this relationship was narrowly nonsignificant $(\mathrm{p}=0.13)$. Yet, it is worth noting that the nonsignificant findings may reflect various shortcomings of the data, including the relatively small sample sizes (which reduces statistical power) and the coarseness of the measures. For instance, while the technology distribution measure captured the range of types of devices distributed, it did not reflect the number of students reached through those distributions.

Taken together, these results indicated substantial remaining variability in fall readiness measures. They also suggested positive associations between prior DE learning resources and fall 2020 readiness measures, and possibly between emergency responses and fall readiness measures, although our limited statistical power cautions against over-interpreting those relationships. 


\section{Figure 2.}

Path Analysis Model Estimates of Relationships between Fall Readiness Measures and Selected Emergency Responses, Pre-COVID DE Resources, and Institutional Characteristics.



\section{Panel B. Fall Faculty Training Scale (Std.)}

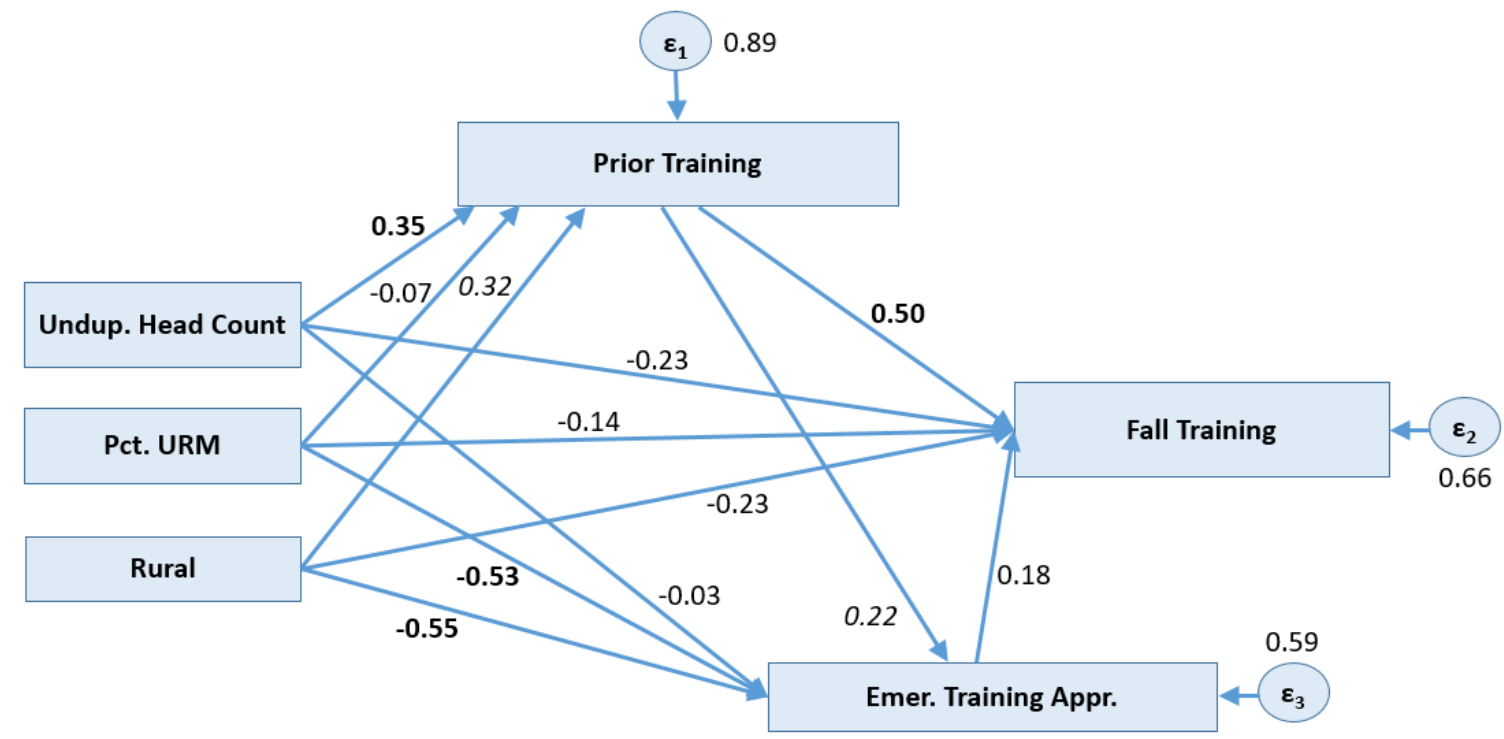

Note: Italicized coefficients significant at $\mathrm{p}<0.10$. Bold cofficients significant at $\mathrm{p}<0.05$. 


\section{Discussion}

Our analysis yielded several implications. First, there was significant variability within the system prior to COVID-19 on DE resources like training, student technology barriers to accessing virtual courses, and virtual student services access. The latter particularly was at least partly related to membership in the CVC-OEI consortium. Interestingly, pre-COVID DE resources at the institutional level were, for the most part, not strongly related to student demographics like the share of underrepresented minority students or share of Pell-receiving students. However, these factors were related to the students' technology-related barriers to access.

The variation in pre-COVID DE resources suggests that there was variability in how wellpositioned campuses were to address the crisis by mobilizing existing DE resources. This was reflected in our regression analyses, which found that colleges with higher pre-COVID levels of DE resources were able to translate that into broader training efforts (e.g., training students in a greater variety of online learning skills and offering a greater number of approaches to training faculty). While the relationship between such emergency responses and fall readiness measures was not statistically significant, this was likely partly an artifact of our limited statistical power.

An important implication of our findings that prior resources were related to responses is that college systems nationwide should stand ready to mobilize resources to help campuses with lower initial levels of DE learning resources mount responses to the COVID-19 crisis. This may take the form of either financial aid or technical assistance. The California Community College system, for instance, disseminated faculty training resources such as online teaching tutorials through bodies like@ONE, the training arm of the CVC-OEI. Both consortium member colleges and non-member colleges could tap many of these resources. Lending context to the importance of these resources, one survey respondent noted, "We were tapping into as many OEI programs as possible and... attending as many statewide meetings to stay informed as possible.... Greatly value all of the OEI and @ONE resources that have been available." Another respondent shared, "we would have been lost without the help and resources from the CVC-OEI." Indeed, the availability of such resources systemwide may have attenuated the relationships between pre-COVID DE learning resources and fall readiness measures in factors like training, and the suggestive resource gaps we observed may have been larger absent the ability to leverage expertise through bodies like the CVC-OEI to support colleges systemwide.

Second, we observed significant efforts across the system to address the COVID-19 crisis. Notably, all campuses reported technology distribution efforts that included distributing personal computing devices (laptops or Chromebooks), and many attended to addressing other issues such as connectivity (through hotspot distribution) or smoothing participation in Zoom calls (through headset and webcam distribution). Campuses also offered students training in a broad number of skill domains conducive to online learning and took a broad variety of approaches in supporting and training faculty to move classes online. Campuses that previously lacked either virtual tutoring or counseling almost universally adopted virtual options for both.

Finally, these efforts seemed to be associated with improved readiness for the fall 2020 term. Far more faculty were projected to be trained in all skills examined in fall compared to in the pre-COVID period, and respondents estimated that fewer students would face barriers accessing remote classes in the fall compared to in the spring prior to technology distribution efforts. That said, on average responding colleges estimated that $30 \%$ of students would continue 
to face barriers to accessing online classes for the fall term, suggesting considerable remaining need.

Our survey data has important limitations. First, we received responses from only 45 colleges, representing $40 \%$ of colleges across the California Community College system. While respondent and non-respondent colleges resemble each other on observed characteristics, the respondent colleges may be unrepresentative on unobserved dimensions. Less speculatively, the relatively small sample size yielded relatively little power to detect relationships between variables, and so our results - particularly the path analysis models, where our sample-size-toparameter relationships are lower than ideal—must be interpreted with caution.

Second, our measures are relatively coarse and do not nearly capture the range of efforts put forth by California Community Colleges during the current crisis. For instance, while our emergency response variable captures the breadth in approaches to training, it does not capture other dimensions of the strength of training responses such as the number of faculty members trained. The open-ended comments in our surveys give some sense of the intensity of these efforts. One respondent noted that "the faculty as a whole rose to the occasion." Their campus did "massive training starting in March and through summer" with the help of four "star faculty" brought in to help facilitate the training. They trained approximately 250 faculty, with "approximately 170 [completing an] intensive eight-week training."

Despite these limitations, this study establishes the considerable variability in the system in terms of pre-COVID DE learning resources; the considerable strength of responses system-wide to the current crisis; and the considerable needs that colleges still have to support students and meet the current challenge. Future work should build on these foundations to establish efforts that colleges are able to effectively employ to quickly bolster access to online courses and improve course quality, and that community college systems are able to use to support colleges in these goals.

\section{Acknowledgements}

The authors gratefully acknowledge financial support from the Spencer Foundation to the first author (Grant \# 202100019). We thank the California Community Colleges Chancellor's Office for providing data on online course-taking. This study is a subproject under a study on outcomes for students in California Community Colleges by Michal Kurlaender, whom we thank as well. We thank the Distance Education Coordinators Organization for providing information about the study to systemwide distance education leaders. We thank Jim Julius, Kandace Knudson, Michael Smedshammer, Nicole Sparapani, and participants in the Education Research Initiative seminar at UC Irvine for feedback at various stages of conceptualizing this project. Finally, our sincere thanks to all distance education leaders who participated in the COVID-19 Distance Education Leaders Survey. All errors are solely ours. 


\section{References}

Allen, I. E., \& Seaman, J. (2014). Grade change: Tracking online education in the United States. Babson Survey Research Group. https://www.onlinelearningsurvey.com/reports/gradechange.pdf

Bambara, C. S., Harbour, C. P., Davies, T. G., \& Athey, S. (2009). Delicate engagement: The lived experience of community college students enrolled in high-risk online courses. Community College Review, 36(3), 219-238.

Bentler, P. M., \& Chou, C.-P. (1987). Practical issues in structural equation modeling. Sociological Methods and Research, 16(1), 78-117.

Bettinger, E. P., Fox, L., Loeb, S., \& Taylor, E. S. (2017). Virtual classrooms: How online college courses affect student success. American Economic Review, 107(9), 2855-2875. https://doi.org/10.1257/aer.20151193

Brooks, C., \& Grajek, S. (2020). Faculty readiness to begin fully remote teaching. Data Bytes. https://er.educause.edu/blogs/2020/3/faculty-readiness-to-begin-fully-remote-teaching

Chen, G. (2018, November 17). Online courses popularity growing at community colleges. Community College Review. https://www.communitycollegereview.com/blog/onlinecourses-popularity-growing-at-community-colleges

Cox, R.D. (2005). Online education as institutional myth: Rituals and realities at community colleges. Teachers College Record, 107(8), 1754-1787. https://doi.org/10.1111/j.14679620.2005.00541.x

The Education Trust-West. (2020, October 6). The digital divide in higher education. The Education Trust-West. https://west.edtrust.org/resource/the-digital-divide-in-higher-ed/

Githens, R. P., Sauer, T. M., Crawford, F. L., Cumberland, D. M., \& Wilson, K. B. (2014). Online workforce development in community colleges: Connection with community, institutional, and governance factors. Community College Review, 42(4), 283-306.

Gower, J. C. (1971). A general coefficient of similarity and some of its properties. Biometrics, 27(4), 857-871.

Grandzol, C.J. (2006). Best practices for online business education. International Review of Research in Open and Distributed Learning, 7(1), 1-18

Guglielmino, L. M., \& Guglielmino, P. J. (2003). Identifying learners who are ready for elearning and supporting their success. In G. M. Piskurich, Preparing learners for elearning (pp. 19-33). Jossey-Bass/Pfeiffer.

Harasim, L., Hiltz, S. R., Teles, L., \& Turoff, M. (2001). Learning networks: A field guide to teaching and learning online. MIT Press.

Hart, C. M. D., Freidmann, E., \& Hill, M. (2018). Online course-taking and student outcomes in California community colleges. Education Finance and Policy, 13(1), 42-71. https://doi.org/10.1162/EDFP_a_00218 
Hill, M. S. (2019). Nontraditional and the new normal: Three studies on nontraditional student pathways in higher education (Publication No. 2309856041) [Doctoral dissertation, University of California, Davis]. ProQuest Dissertations \& Theses Global. https://search.proquest.com/docview/2309856041

Hodges, C., Moore, S., Lockee, B., Trust, T., \& Bond, A. (2020, March 27). The difference between emergency remote teaching and online learning. Educase.

https://er.educause.edu/articles/2020/3/the-difference-between-emergency-remote-teachingand-online-learning

Huguet, P., Dumas, F., Monteil, J. M., \& Genestoux, N. (2001). Social comparison choices in the classroom: Further evidence for students' upward comparison tendency and its beneficial impact on performance. European Journal of Social Psychology, 31(5), 557-578.

Jaggars, S. (2011). Online learning: Does it help low-income and underprepared students? Community College Research Center, Teachers College, Columbia University, Working Paper 26. https://academiccommons.columbia.edu/doi/10.7916/D82R40WD

Johnson, H. P., Mejia, M. C., \& Cook, K. (2015). Successful online courses in California's community colleges. Public Policy Institute.

https://www.ppic.org/content/pubs/report/R_615HJR.pdf

Johnson, S. G., \& Berge, Z. (2012). Online education in the community college. Community College Journal of Research and Practice, 36(11), 897-902.

Kearney, M., \& Maher, D. (2013). Mobile learning in maths teacher education: Using iPads to support pre-service teachers' professional development. Australian Educational Computing, 27(3), 76-84.

Lee, Y. C. (2008). The role of perceived resources in online learning adoption. Computers \& Education, 50(4), 1423-1438.

Lockyer, L., \& Bennett, S. (2006). Understanding roles within technology supported teaching and learning: Implications for staff, academic units, and institutions. In J. O'Donoghue (Ed.), Technology Supported Learning and Teaching: A Staff Perspective (pp. 210-223). IGI Global.

Martins, J. T., \& Baptista Nunes, M. (2016). Academics' e-learning adoption in higher education institutions: A matter of trust. Learning Organization, 23(5), 299-331. https://doi.org/10.1108/TLO-05-2015-0034

McCarthy, S., \& Samors, R. (2009). Online learning as a strategic asset, Vol. 1: A resource for campus leaders. Association of Public and Land-Grant Universities.

Moore, M.G. (1989). Three types of interaction. The American Journal of Distance Education, $3(2), 1-7$.

Muljana, P. S., \& Luo, T. (2019). Factors contributing to student retention in online learning and recommended strategies for improvement: A systematic literature review. Journal of Information Technology Education: Research, 18, 19-57.

Nissenbaum, H., \& Walker, D. (1998). A grounded approach to social and ethical concerns about technology and education. Journal of Educational Computing Research, 19(4), 411-432. 
Pacansky-Brock, M., Smedshammer, M., \& Vincent-Layton, K. (2020). Humanizing online teaching to equitize higher education. Current Issues in Education, 21(2), 1-21. https://cie.asu.edu/ojs/index.php/cieatasu/article/view/1905/870.

Quintana, C., Zhang, M., \& Krajcik, J. (2005). A framework for supporting metacognitive aspects of online inquiry through software-based scaffolding. Educational Psychologist, 40(4), 235-244.

Richardson, J. C., Koehler, A. A., Besser, E. D., Caskurlu, S., Lim, J., \& Mueller, C. M. (2015). Conceptualizing and investigating instructor presence in online learning environments. The International Review of Research in Open and Distributed Learning, 16(3).

Rovai, A. P. (2003). In search of higher persistence rates in distance education online programs. The Internet and Higher Education, 6(1), 1-16.

Shepherd, C. E., Bolliger, D. U., Dousay, T. A., \& Persichitte, K. (2016). Preparing teachers for online instruction with a graduate certificate program. TechTrends, 60(1), 41-47.

Thistoll, T., \& Yates, A. (2016). Improving course completions in distance education: An institutional case study. Distance Education, 37(2), 180-195.

U.S. Department of Education, National Center for Education Statistics, Integrated Postsecondary Data System (IPEDS) (2018). https://nces.ed.gov/ipeds/Content/files/2017047_web.pdf

Varvel, V. E. (2007). Master online teacher competencies. Online Journal of Distance Learning Administration, 10(1). https://www2.westga.edu/ distance/ojdla/spring101/varvel101.htm

Xu, D., \& Jaggars, S. S. (2014). Performance gaps between online and face-to-face courses: Differences across types of students and academic subject areas. The Journal of Higher Education, 85(5), 633-659. https://doi.org/10.1353/jhe.2014.0028

Xu, D., \& Jaggars, S. S. (2013). The impact of online learning on students' course outcomes: Evidence from a large community and technical college system. Economics of Education Review, 37, 46-57. https://doi.org/10.1016/j.econedurev.2013.08.001 


\section{Appendix A: Supplementary Figures and Tables}

\section{Appendix Figure OA1.}

Dendrogram: Complete-Linkage Cluster Analysis of Pre-COVID DE Resources

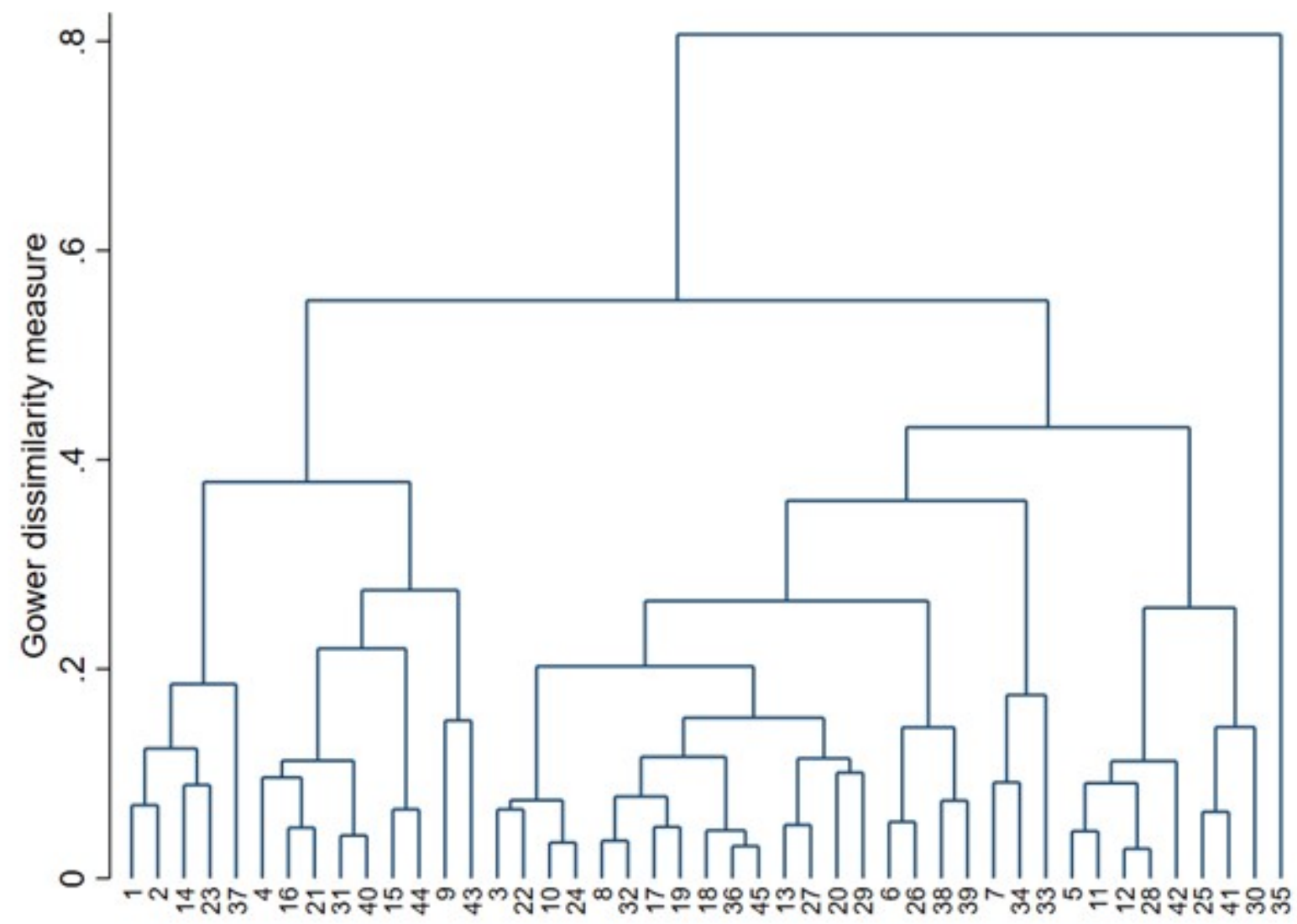




\section{Appendix Table OA1}

Comparison of Pre-COVID Institutional Characteristics: Responding vs. Non-Responding Institutions

\begin{tabular}{lccc}
\hline & $\begin{array}{c}(1) \\
\text { Non- } \\
\text { Responding } \\
\text { Colleges }\end{array}$ & $\begin{array}{c}\text { Responding } \\
\text { Colleges }\end{array}$ & $\begin{array}{c}\text { P-value of } \\
\text { Diff }\end{array}$ \\
\hline $\begin{array}{l}\text { Pre-COVID Student Demographic Characteristics } \\
\text { Share URM (\%) }\end{array}$ & 60 & 58 & 0.612 \\
Share Pell (\%) & 46 & 48 & 0.51 \\
Pre-COVID Institutional Characteristics & & & \\
Instructional Expense/FTE (\$1000s) & 5.699 & 5.906 & 0.554 \\
Unduplicated Head Count (1000s) & 19.842 & 18.318 & 0.454 \\
Rural & 0.116 & 0.111 & 0.937 \\
Urban & 0.449 & 0.400 & 0.607 \\
Multi-College District & 0.565 & 0.578 & 0.896 \\
CVC Consortium College & 0.464 & 0.533 & 0.472 \\
Pre-COVID DE Penetration & & & \\
\% Courses Offered Online & 22 & 21 & 0.666 \\
\hline $\mathrm{N}$ & 69 & 45 & \\
\hline Estmates are unweighted. & & & \\
\hline
\end{tabular}

Estimates are unweighted. $* * * \mathrm{p}<.01, * *, \mathrm{p}<.05, * \mathrm{p}<.10$.

$\mathrm{URM}=$ Underrepresented minorities, and includes students classified as American Indian/Native Alaskan; Black/African American; Hispanic/Latino; multi-racial; or of unknown race. Pell receipt captures share of first-time undergraduates using Pell. \% Courses Offered Online captures the share of courses where at least one section was offered online in 2018-19. 


\section{Appendix Table OA2}

Description of Measures

\begin{tabular}{|c|c|}
\hline Measure & Construction \\
\hline \multicolumn{2}{|c|}{ Pre-COVID Demographic and Institutional Characteristics } \\
\hline \multicolumn{2}{|l|}{ Constructed From IPEDS, 2017-18: } \\
\hline Share URM (\%) & Summed IPEDS variables: percent of total enrollment \\
\hline & American Indian/Alaska Native, Black/African \\
\hline & American, Hispanic/Latino, Unknown Race, or \\
\hline & Multiracial (DRVEF2018) \\
\hline Share Pell (\%) & $\begin{array}{l}\text { Given in IPEDS: Percent of full-time first-time } \\
\text { undergraduates awarded Pell grants (SFA1718) }\end{array}$ \\
\hline Instructional Expense/FTE $(\$ 1,000 \mathrm{~s})$ & $\begin{array}{l}\text { IPEDS variable on instruction expenses per FTE (GASB) } \\
\text { (DRVF2018), divided by } 1000\end{array}$ \\
\hline Unduplicated Head Count $(1,000 \mathrm{~s})$ & $\begin{array}{l}\text { IPEDS variable on 12-month unduplicated head count for } \\
\text { 2017-18 (DRVEF122018_RV), divided by } 1000\end{array}$ \\
\hline Rural & $\begin{array}{l}\text { IPEDS variable on degree of urbanization (HD2018). } \\
\text { School is rural if it was classified as Rural, Fringe } \\
(\text { HD2018 = 41) or Rural, Distant (HD2018 = 42) }\end{array}$ \\
\hline Urban & $\begin{array}{l}\text { IPEDS variable on degree of urbanization (HD2018). } \\
\text { School is rural if it was classified as City, Large } \\
\text { (HD2018=11), City Mid-size (HD2018 = 12) or City, } \\
\text { Small (HD2018 = 13) }\end{array}$ \\
\hline \multicolumn{2}{|l|}{ Constructed from CCCCO, 2018-19: } \\
\hline Multi-College District & $\begin{array}{l}\text { College ID number in CCCCO data (ST_COLLEGE_ID) } \\
\text { includes district information in first two digits. Indicator } \\
\text { for whether multiple colleges shared the same district } \\
\text { identifier }\end{array}$ \\
\hline $\begin{array}{l}\text { Constructed from Publicly Available Lis } \\
\text { CVC Consortium College }\end{array}$ & $\begin{array}{l}\text { List of colleges available at https://cvc.edu/about-the- } \\
\text { oei/college-participation/ }\end{array}$ \\
\hline
\end{tabular}

\section{Pre-COVID Online Learning Resources}

Constructed from CCCCO, 2018-19:

Courses with Any Online Section (\%)

Constructed from CDELS:

Share: Tech Access Barriers, Spring

$(\%)$

DE Personnel per 1000 Students

Virtual Tutoring and Counseling Available Pre-COVID
Each class offered in 2018-19 was coded 0 if no sections were offered virtually or 1 if one or more section was offered virtually.

Respondents estimated the share of students who would have faced difficulty accessing emergency remote classes during the COVID-19 crisis in spring (e.g., due to lack of devices/connectivity) without campus efforts to distribute devices/WiFi access

Respondents estimated the number of full-time equivalent DE personnel. Estimate of fall full-time equivalent student enrollment taken from 2017-18 IPEDS (DRVEF2018)

Respondents reported on availability of tutoring virtually either through campus tutoring centers, through outside providers (like NetTutor), tutoring consortiums. Respondents reported on whether counseling (academic, 


\section{Pre-COVID Faculty Training Scale} (Std.) career, or personal) was available through virtual meeting software like Zoom or Cranium Café. Colleges received a value of 1 if both counseling and tutoring were available virtually, or 0 if either service was not available virtually. Respondents reported on the share (\%) of faculty teaching online who were trained in each of 9 skills: Canvas/LMS skills; Zoom skills; structure/organization in online courses; accessibility to students with disabilities; personalizing/humanizing instruction; promoting equity in online learning; assessments in online learning; promoting student-student interaction; and promoting student-instructor interaction/regular effective contact. We standardized responses for each skill, averaged the standardized skill measures, and restandardized the resulting average to have a mean of 0 and standard deviation of 1 .

\section{Emergency Responses during COVID-19 Crisis}

Constructed from CDELS:

Num. Device Types Distributed

Num. Domains of Student Skill Training

\footnotetext{
Adopted Virtual Tutoring or Counseling Number of Emergency Faculty Training Approaches
}

Respondents reported on whether each of the following types of technology was distributed: Laptops, Chromebooks, headsets, webcams, or mobile hotspots. Because laptops and Chromebooks are both personal computing devices, we combined those into a single personal computing indicator. We then added the binary indicators for whether each device type was distributed, generating a count of types of devices distributed. Respondents reported on whether their campuses offered training in eight different areas of skills whose classes were moved online: Canvas skills, Zoom skills, managing interaction in online classes, study skills for online classes, accessing student services remotely, training in the technical requirements needed to connect to online classes, training to use particular devices (e.g., Chromebooks) or training to use particular products (e.g., Proctorio). Each skill was coded 0/1, and we added these indicators to generate count of the number of different skill domains in which colleges offered training. In practice, since all colleges had some form of virtual tutoring, this was driven by adoption of virtual counseling. Respondents reported on whether academic, career, or personal counseling services were available using virtual meeting software such as Zoom. Colleges that did not have virtual counseling pre-Zoom but adopted it prior to fall were coded as 1; colleges that did not have virtual counseling in any domains as of fall, or that previously had virtual counseling in place (and were not newly adopting it), were coded with values of 0 . 


\section{Fall 2020 Readiness Measures}

\section{Constructed from CDELS:}

Share: Tech Access Barriers, Fall (\%) Respondents estimated the share of students who would faced difficulty accessing emergency remote classes in the Fall

Fall Faculty Training Scale (Std.)

Respondents reported on the share (\%) of faculty teaching online who were trained in each of 9 skills:

Canvas/LMS skills; Zoom skills; structure/organization in online courses; accessibility to students with disabilities; personalizing/humanizing instruction; promoting equity in online learning; assessments in online learning; promoting student-student interaction; and promoting student-instructor interaction/regular effective contact. We standardized responses for each skill, averaged the standardized skill measures, and restandardized the resulting average to have a mean of 0 and standard deviation of 1 .

Virtual Tutoring and Counseling Set to 1 if both tutoring and counseling were available Available: Fall prior to COVID-19, or if colleges adopted any missing services during the crisis. 


\section{Table OA3}

Path Analysis Models (Standardized): Tabular Form

\begin{tabular}{|c|c|c|}
\hline & $\begin{array}{c}\text { Stud. Facing } \\
\text { Access Barriers: } \\
\text { Fall (\%) } \\
(1) \\
\end{array}$ & $\begin{array}{c}\text { Fall Faculty } \\
\text { Training Scale } \\
\text { (Std.) } \\
(2)\end{array}$ \\
\hline \multicolumn{3}{|c|}{ Paths: Institutional Characteristics $=>$ Focal Pre-COVID DE Resource } \\
\hline Share URM (\%) & $\begin{array}{l}0.70^{* * *} \\
(0.17)\end{array}$ & $\begin{array}{l}-0.07 \\
(0.16)\end{array}$ \\
\hline Unduplicated Head Count (1000s) & $\begin{array}{l}-0.21 \\
(0.15)\end{array}$ & $\begin{array}{l}0.35^{* *} \\
(0.17)\end{array}$ \\
\hline Share Pell (\%) & $\begin{array}{c}-0.63 * * * \\
(0.17)\end{array}$ & \\
\hline Rural & $\begin{array}{l}0.41 * * \\
(0.17)\end{array}$ & $\begin{array}{l}0.32 * \\
(0.18)\end{array}$ \\
\hline \multicolumn{3}{|c|}{$\begin{array}{l}\text { Paths: Institutional Characteristics and Focal Pre-COVID DE Resource } \\
\text { =>Focal Emergency Response }\end{array}$} \\
\hline Focal Pre-COVID DE Resource & $\begin{array}{l}0.41 * * * \\
(0.15)\end{array}$ & $\begin{array}{l}0.22^{*} \\
(0.13)\end{array}$ \\
\hline Share URM $(\%)$ & $\begin{array}{c}-0.44^{* *} \\
(0.22)\end{array}$ & $\begin{array}{c}-0.53 * * * \\
(0.11)\end{array}$ \\
\hline Unduplicated Head Count (1000s) & $\begin{array}{l}-0.30^{*} \\
(0.15)\end{array}$ & $\begin{array}{l}-0.03 \\
(0.15)\end{array}$ \\
\hline Share Pell (\%) & $\begin{array}{l}0.46^{* *} \\
(0.21)\end{array}$ & \\
\hline Rural & $\begin{array}{c}-0.50 * * * \\
(0.18) \\
\end{array}$ & $\begin{array}{c}-0.55 * * * \\
(0.14) \\
\end{array}$ \\
\hline \multicolumn{3}{|c|}{$\begin{array}{l}\text { Paths: Institutional Characteristics, Focal Pre-COVID DE } \\
\text { Resources, and Focal Emergency Response =>Fall Readiness Measure }\end{array}$} \\
\hline Focal Pre-COVID DE Resource & $\begin{array}{c}0.79 * * * \\
(0.12)\end{array}$ & $\begin{array}{c}0.50 * * * \\
(0.13)\end{array}$ \\
\hline Focal Emergency Response & $\begin{array}{l}-0.20 \\
(0.13)\end{array}$ & $\begin{array}{c}0.18 \\
(0.16)\end{array}$ \\
\hline Share URM (\%) & $\begin{array}{c}-0.48^{* *} \\
(0.19)\end{array}$ & $\begin{array}{l}-0.14 \\
(0.16)\end{array}$ \\
\hline Unduplicated Head Count (1000s) & $\begin{array}{c}0.03 \\
(0.14)\end{array}$ & $\begin{array}{l}-0.23 \\
(0.16)\end{array}$ \\
\hline Share Pell (\%) & $\begin{array}{l}0.37^{*} \\
(0.19)\end{array}$ & \\
\hline Rural & $\begin{array}{l}-0.14 \\
(0.18)\end{array}$ & $\begin{array}{l}-0.23 \\
(0.19)\end{array}$ \\
\hline \multicolumn{3}{|c|}{ Goodness of Fit Measures } \\
\hline Coefficient of Determination $\left(\mathrm{R}^{2}\right)$ & 0.49 & 0.49 \\
\hline RMSEA & 0.00 & 0.00 \\
\hline Comparative Fit Index & 1.00 & 1.00 \\
\hline $\mathrm{N}$ & 43 & 41 \\
\hline
\end{tabular}

Standardized, unweighted models. For the "Students Facing Access Barriers (Fall)" measure, the focal pre-COVID DE resource is the spring version of the same measure, and the focal emergency response is the number of different types of technology distributed. For the "Fall Faculty Training Scale" measure, the focal pre-COVID DE resource is the spring version of the same measure, and the focal emergency response is the number of approaches to faculty training. 